\title{
THE UNMAKING OF ROMA STUDENTS: CONTRIBUTING FROM A CRITICAL AND ENGAGED ETHNOGRAPHY
}

\author{
KITTI BARACSI ${ }^{1}$
}

\begin{abstract}
In this study, the focus is put on the process by which the different educational actors - in this case mostly teachers - produce the image of Roma students and how a critical and engaged ethnography can show how ideas related to Roma culture, identity and integration play a role in the making of Roma students. Through this we can understand more thoroughly how the processes through which the categories that are meant to interpret the complexity of social processes or bring about positive changes become instruments that actually reinforce discriminative practices.
\end{abstract}

Keywords: Roma students, education, engaged ethnography, collaborative research, teacher narratives

Summary: I. IntRoduction; II. The ConteXt; III. Considerations about the Methodology, Research Process and Position; III.1 Methodology; III.2 The research process; III.3 The researcher's position; IV. CRITICAL AND ENGAGED AT THE SAME TIME?; IV.1 Challenges and limits of attempting to have an engaged position; IV.2. Transgression at the service of critical ethnography?; V. CONCLUSION

\section{INTRODUCTION}

McDermott and Varenne (2006), in their study "Reconstructing Culture in Educational Research" discuss how culture can be reconstructed through educational research. Based on the experiences of their work on success and failure (Varenne \& McDermott, 1998), they adopt a critical stand that intends to reveal what some taken-forgranted categories imply: "A cultural analysis is not about giving solutions to acknowledged and likely false problems, but about sketching and confronting the conditions that tied problems and apparent solutions together.” (McDermott \& Varenne, 2006: 13) At the same time, they reflect on the limits of the cultural approach and call attention on its grounding in institution and time. As they highlight, "it might be best to forget individual children and focus instead on how we have created contexts that make some children -about half of them- so problematic. If schools are for all children to flourish, then the individual child can be our unit of concern, but not our unit of analysis or

\footnotetext{
${ }^{1}$ Education and Society Doctoral School of Education, University of Pécs (kitti.baracsi@gmail.com).
} 
reorganization. Why should kids be the focus of change when it is the rest of us -the culture that is acquiring them- that arrange their trouble?” (McDermott \& Varenne, 2006:4) This article seeks to understand how such a reconstruction of culture through educational research can be applied from an engaged and collaborative research position to understand the ways in which teachers, educators and social workers ${ }^{2}$ produce the image of Roma students in relation to existing policy categories.

The empirical basis of this article comes from a Ph.D. research conducted in Pécs, Hungary and in Naples, Italy between 2011 and 2016. The research focuses on the dynamics of local actors in relation to policy discourses by analysing their narratives and strategies in the "making of Roma students" and investigating how this is connected to the making of the periphery. It explores the ways in which local actors -teachers, students, educators, social workers and families- respond, resist, redesign or adapt to policies in contexts considered to be peripheral and how these contexts are produced within these narratives. The narratives of different actors, with a special focus on conflictive situations are analysed along the main categories and terms that emerge in Roma policies related to education (like early marriage, segregation, disadvantages, among others). 'Roma policies', in my study, refer to policies that address Roma -implicitly or explicitly ${ }^{3}$ - as a target group, whereas 'Roma' -for an analytical purpose- refers to those who are considered to be 'Roma' in the aforementioned policies and by the local actors. Drawing on this empirical data, the current study gives examples of research scenarios in which the abovementioned critical and engaged position made a significant difference in the interpretation of teachers', educators' or social workers' narratives about Roma students.

\section{THE CONTEXT}

It might seem surprising, given the dimensions and social processes of Naples and Pécs, that I have chosen to compare these two localities. Nevertheless, by contrasting two very different contexts, similar elements that have an impact on the production of the "Roma issue" become more visible. Although these peripheries, which are embedded into very different contexts, differ greatly, they also share similar processes and representations. For instance, the ghettos ${ }^{4}$ and the camps, the locations of my research have a particular relation to time and space, and the 'permanent temporariness' (Picker \& Pasquetti, 2015) is an important characteristic they share.

\footnotetext{
${ }^{2}$ In this particular context, it refers mainly to NGO employees, as the social and educational projects that target Roma students are mainly outsourced to NGOs.

${ }^{3}$ By Roma targeted policies I refer both to policies that explicitly use the term Roma (or other common designations of the analysed contexts, e.g. Nomad, Gypsy, etc.), but also to those that avoid ethnic targeting and use socioeconomic categories and/or spatial definitions that in the local context carry a similar ethnic load.

${ }^{4}$ Although using the concept of ghetto in the Hungarian context is questionable, I will use this term for the sake of simplicity.
} 
When understanding the contexts of my fieldwork, in addition to learning 'the facts' about these neighbourhoods, understanding the history of knowledge production of these places -namely how and to whom they constitute an important topic of study and are defined as camp, periphery or deprived areas- seems to be even more important. In this regard, I would like to highlight that I do not look at the Roma camp or ghetto itself (leaving aside my concern about camp and ghetto definitions ${ }^{5}$ ) but the dynamic relation between camp and periphery, as well as among ghetto and periphery.

\section{Naples}

When I started to work in Naples in 2011 as a trainee at an association, I suddenly found myself in Scampia, a periphery that has an overall negative fame both in Italy and the world. In fact, it has inspired several books and films, including Roberto Saviano's famous non-fiction investigative book, Gomorrah (Saviano, 2006). The homonymous TV series also takes place here. I lived in 'popular neighbourhoods' of the centre, but right from the start I spent most of my time in Scampia and in the Roma camps around the city. I began to understand the city from its margins, taking the experiences of the periphery as a basic reference point. This turned out to be quite fruitful for my research, considering that the place I was analysing was highly stigmatized also by the inhabitants of the city. The process by which stigmas are transferred is complex and multi-layered: Neapolitans are stigmatised by the rest of Italy, but then stigmas are also visible within the city and among the neighbourhoods and social groups.

Naples, which is a popular place for research, has been widely represented and eventually stereotyped even in scientific works. On the other hand, there are important contributions that analyse everyday life in popular neighbourhoods (probably the most famous one being Belmonte, 1983) and the role of informality in "managing existence" (see: Pardo, 1996) Dines supports a critical ethnography of Naples, based on the concept of an "ordinary city" (Robinson, 2006), among others. Based on this concept, Naples is as diverse, dynamic and conflicted as any other city. (Dines, 2012b) Such a critical ethnography, as Dines suggests, "needs to engage more seriously with analogous urban processes of other cities, be they Stockholm or Delhi, rather than measuring Naples exclusively against the rest of Italy or Mediterranean Europe. Second, it is necessary to oust the city's historic centre from anthropology's pantheon of privileged field sites and to revisit it as one part of an ordinary city interconnected with the world at large. Third, greater scrutiny must be paid to the interactions and conflicts between different social groups and how these are constitutive of urban life [...]” (Dines, 2012a: 23).

The so-called "old camp" (the "new camp” is in Secondigliano, it is a formal one) is located on the Northern periphery of Naples, in Scampia. This district faces a series of

\footnotetext{
${ }^{5}$ More about the conceptualization of camp, see for instance: Agamben, 1996; Agier; 2002 or about governing Roma camps in the Italian context, see: Sigona, 2006, 2011, 2015 and Picker, 2012
} 
problems and many of them are the result of failed urban plans and their implementation, given that several important social and cultural factors ${ }^{6}$ were neglected because of different intervening interests. Though the image of the Roma camp - which is located right next to a recycling depot, literally crosscutting a road leading out of the city - makes us believe that the Roma are the "newcomers", the truth is that both Neapolitans and Roma migrated to this territory relatively recently. The real expansion of the neighbourhood took place in the '80s and tried to solve housing problems that emerged after the earthquake. This internal migration was followed by a 'spontaneous' migration of people from Yugoslavia, which transformed into an inflow during the war in the '90s. ${ }^{7}$ The camp, despite the external perceptions, is not a homogeneous community, not only in terms of ethnic belonging but also because of socio-economic status. Public authorities, in their interventions, often overlook this stratification within the segregated Roma communities, though the latest census seems to show that there is a growing interest in mapping sociological factors.

Barra is another, although less known, Neapolitan periphery and it has some characteristics that are similar to those of Scampia: a high level of unemployment and strong presence of criminality, which have an effect on education. In this context, we can find an informal camp close to the railway line that is visible from the train but hidden from the usual routes of the local population. The camp has existed for over a decade and its inhabitants, who are from Romania (mainly from Călărași), identify themselves as 'spoitori' to emphatically differentiate themselves from other Roma groups in Naples. As a matter of fact, they often refuse to acknowledge the term "Roma" when referring to their ethnic identification. According to different estimates dating back to a couple of years ago, 200-350 persons live on this territory (Zoppoli \& Saudino, 2012).

Regarding schooling, the two neighbourhoods share similar problems, both regarding Neapolitan and Roma children ${ }^{8}$. Associations and schools notice a progress in

\footnotetext{
${ }^{6}$ About Scampia in English see Laino (2005). Some accounts about the topic (e.g. interviews) of Felice Pignataro, who was an artist and activist are also interesting. Documentary: 'Felice!' http://www.felicepignataro.org/felice/

7 The first official data about the camp's population was the one collected in 2008 when the state of emergency was declared (Censimento - Prefettura di Napoli Commisario Delegato per l'emergenza insediamenti comunità nomadi nella regione Campania O.P.C.M. 3678 del 30 maggio 2008). The newest data (mapping survey, a Romact and Welfare Department Joint Action) that was presented publicly at the Faculty of Architecture by Giovanni Laino on November 9, 2015 shows a decline in the population compared to the previous data. According to this data, there are 681 persons living on this territory and half of them were born in Italy. There are several methodological and ethical concerns regarding these surveys, so data must be treated with some caution. However, the growing interest of the city to obtain a more complex picture about the background and needs of this community can be considered as progress.

${ }^{8}$ The distinction between Neapolitans and Roma throughout the text comes from the self-identification of actors, which in these cases often includes an ethnic load (also in terms of differentiating Neapolitans from Italians), while I find it important to stress how much local identity becomes important to Roma students, for instance, not only in terms of belonging to the city, but also to their neighbourhood.
} 
reference to the low school attendance of Roma children, which is more visible in Barra than in Scampia (especially taking into account their long presence on the territory). Nevertheless, school dropouts, the so-called early marriage and the participation of minors in the informal economy are still among the most mentioned problems. In terms of institutional context, in Scampia I focused on the educational institute that includes the three elementary schools, which accept most of the children from the camp. In Barra, out of two elementary schools (which belong to the same institute), I have chosen the one that has the highest presence of Roma children. Later on, I included the first grade of a secondary school in which students usually continue their educational pathway. The education of Roma students often based on social, rather than educational policies - is approached by public interventions as if it were a shared issue of public schools and NGOs, often counting on their presence within the school. Scampia, in general, is a place in which several initiatives take place and several religious groups and associations are present in the camp. Most of them also carry out educational activities. There are fewer NGOs in Barra, but the dimensions are smaller. Regarding the projects, in both territories there is some kind of collaboration between the different actors, though it is not very organized and does not seem very efficient. Since the Roma moved to these territories, several public projects were set forth. For many years they have been set in motion under the name of mediation, lately referred to as an inclusion project thanks to the local extension for one year (school year 2014/2015) of a ministerial "experimental project" that started in 2013/2014. ${ }^{9}$

\section{Pécs}

Pécs is a city in the South-Transdanubian Region of Hungary. Over the last years, its population has greatly decreased and its economic situation has worsened, which is a contrasting reality to the city's promoted image of a creative and cultural centre. In 2011, I started the fieldwork at a former mineworker colony. When I decided about the territory, I had a clear intention to go to the 'periphery', which I selected because I had contacts that helped me access it. At the time, that was one of the most 'abandoned' areas in terms of public or civil society interventions ${ }^{10}$. Since the transition and the closure of the mine the territory underwent a strong change in terms of population, which was the result of the outflow of former workers, the inflow of people from villages and the relocation of families

\footnotetext{
${ }^{9}$ Progetto per l'inclusione di bambini e adolescenti rom, sinti e caminanti. For more information see: http://www.lavoro.gov.it/temi-e-priorita/infanzia-e-adolescenza/focus-on/integrazione-rom-sinti-ecaminanti/Pagine/default.aspx It is part of a recent development regarding Roma education in Italy thanks to an experimental project that started in 2014 at a national level. Following this ministerial project, in 2015 the city of Naples allocated all the funds that were previously used to address Roma children school drop to this new approach and expanded the experimental project's intervention to a higher number of schools and classes. The former projects had three main intervention areas: mediation with families - in the camp, "accompagnamento" that is a combination of transport to school and 'mediation', support for Roma students in the class and social-health interventions. The ministerial project is focused on inclusion with interventions for the whole class and trainings for children, but keeps bringing external figures to the school and builds on the mediator role regarding the work of 'housing contexts'.

${ }^{10}$ It has been selected as the intervention area of the Romact program exactly because of this reason.
} 
from the city centre. For decades, in Pécs, evicted inhabitants from the city centre were sent to the very periphery of the city. Considering the transformation processes of these colonies that were already taking place, certain areas ended up being segregated. We can also identify some sub-territories within István-akna and at the most peripheral part we can almost exclusively find Roma families. There are both Boyash and Kolompár ${ }^{11}$ families, as well as some examples of Boyash-Non-Gypsy and Boyash-Kolompár marriages. ${ }^{12}$ In the research I carried out in 2014 I included another territory with a similar past (mineworker colony). My fieldwork took place in the school that is located in this neighbourhood (and has students from the other territory where I first started my fieldwork) and in other three schools, one of which is located in another segregated ${ }^{13}$ area. Three of them belong to the same public institute complex and the church runs one. Children from the aforementioned territories also commute to this school of Meszes, which is a 'mixed territory', even though segregation processes are quite visible, especially regarding the schools (Zolnay, 2008). Another school, where I developed a collaborative research, belongs to the same school centre, but is located in another district. In the segregated territories that were previously mentioned, we can find desegregation and community development interventions since $2008^{14}$ and the actions of NGOs usually include afterschool activities. The interventions in Roma communities, in general, have a strong professional structure and can follow the experiences of similar initiatives that have been developed in the region. ${ }^{15}$

\section{Considerations about the Methodology, Research Process And Position}

\section{III.1 Methodology}

The core reference of this research was the educational ethnography (applied both outside and inside of the school) which works with multiple methods, and as an ultimate goal, the so-called 'collaborative ethnography' that I have tried to put into practice with students, schools, and NGOs, but have found extremely complex to do so based both on its practical aspect and its theoretical implications. However, the conflict of interests, the power relations within the field and my limits regarding balancing between different actors gave me an unexpected insight of the research questions. Considering that, from my point

\footnotetext{
${ }^{11}$ The local name used for those groups who speak Romanes.

${ }^{12}$ There are strong boundaries between the old and new inhabitants and the people who live above or below this territory. Several conflicts have emerged between the newcomers and the people that have been living here for decades.

${ }^{13}$ Segregated in terms of socioeconomic conditions, while the ethnicisation of poverty works towards a false ethnically homogeneous imaginary of these areas.

${ }^{14}$ Jelenlét Program of the Hungarian Maltese Charity Service and desegregation programs under different funding schemes (social and regional development funds of the EU) with the participation of a local Roma NGO.

${ }^{15}$ Pécs and the Transdanubian Region are well known for hosting NGOs that have been working for decades with Roma communities. The Gandhi Secondary School, the Collegium Martineum (currently closed) and the Department of Romology are all found in Pécs.
} 
of view, collaboration must involve a higher level of consciousness and dedication, I do not use this term for the entire research methodology, as I am aware of its shortcomings in my research practice ${ }^{16}$ and that is why I rather use 'engaged research'. Educational ethnography itself is understood as a study that involves a cycle of hypotheses and theory building understood as a process that uses multiple methods and gives great importance to the participants' accounts (Walford, 2008). Along these lines, educational ethnography - just like ethnography - is engaged by definition. Still, in this article, engaged research implies an approach that aims to produce research knowledge and, to some extent, implement it in the local context together with the local actors. It would be possible to further reflect ${ }^{17}$ on the relation of collaborative/community-based/participatory/emancipatory or action research. I opted to use the term "engaged research" to explicitly refer to collaboration or participation based on two reasons: the interconnectedness that exists between these approaches, which seek to reshape power relations and the epistemological basis of "traditional” research approaches; and, as I mentioned earlier, because "collaboration”, "participation" and "empowerment" have been defined and redefined in many different ways throughout the negotiation process of my fieldwork, which cannot be narrowed down to a single approach. Also, regarding our specific topic, there is a strong 'Roma participation' discourse. On one hand, it is somehow expected that research projects about the Roma promote as a basic requirement, their participation. On the other hand, Roma academics claim to transform the status quo of "Roma research" through a fundamental change in power relations and an epistemological turn that involves critical whiteness studies, for instance, and feminist theory ${ }^{18}$. Based on these interpretations we can state that this research rather aimed to involve several actors from the already existing local network of actors in the inquiry process and not only a particular group (e.g. children, families or Roma children, families), at the same time supporting the critical analysis of the Roma student's image. ${ }^{19}$

\footnotetext{
${ }^{16}$ Not only in terms of power relations and conflicting interests. While collaboration also means sharing detailed information about the research purposes, constructing questions together, one of my strongest concerns is how much the scope of Roma students caused distortions. It led the actors to either hide or over represent 'Roma issues'.

17 There are several different interpretations of the relation between collaborative and participatory approaches. I have found Ursula Plesner's proposal for understanding collaborative research interesting, according to her distinction, collaborative research is based on an actor-network theory, while the participatory approaches are based on dialogic ones. It might have interesting implications for this research as well. (Plesner, 2013)

${ }^{18}$ As for example in the Special Issue of the Roma Rights Journal 2015/2 "Nothing About Us Without Us? Roma Participation in Policy Making and Knowledge Production”.

19 There are many ethnographic works on Roma education in Italy and Hungary (see, for instance, Saletti Salza, 2003; Setti, 2015; Bakó, 2009; Kovai, 2011; Gobbo, 2009), while we can find less examples of collaborative research with students in this specific topic, although there are many contributions of 'children as co-researchers’ in other topics of educational ethnography (see, for example, Milstein, 2010; Hohti, 2016)
} 


\section{III.2 The research process}

The research started in 2011, first in Pécs and then in Naples. The first steps involved observation in the neighbourhood/camp and interviewing families. Later on, in 2014 and 2015, school ethnographies and additional fieldwork in the neighbourhoods were carried out and complemented with additional visits in 2016. The research had a strong collaborative element. Collaboration has been defined and materialized in several different ways since 2011, including through collaborative research methods in the classroom, school, and afterschool activities or the preparation of scientific papers on the topic with NGO professionals (Pierro et al., 2014). The original idea of conducting a school ethnography in one or two Hungarian schools was extended to a multi-sited, transnational comparative project, although it is still based on very concrete local cases, two different cities and within them, different neighbourhoods.

The collaborative methods used in the classrooms and the schools included a series of activities. First of all, the students' active participation and collaboration with me as a researcher through class activities, which included the construction of interview questions, negotiation in groups, interviews conducted with each other, group reflections about the process, drafting mental maps and analysing them in couples or groups. In the case of focus groups with adolescents, drawings and discussions about future, gender roles and discrimination in school and debates inspired by videos were carried out. Secondly, the teachers and the directors' participation in the construction, in addition to carrying out and interpreting these activities in the form of interviews and conducting a negotiation process in order to implement the activities together, as well as receiving feedback about them and incorporating their interpretation of the results into my analysis. The first data and proposals for the analysis were brought back to the schools and the collaborative analysis process will be extended during the upcoming months.

Along with these activities, I conducted interviews with families and students, teachers, special educators, social services and NGOs. These interviews, together with the field notes, were taken during visits to families or other contexts. I took part in a few meetings of policy-makers, some of NGOs, and collected a wide range of related documents, especially from the local level.

In a relatively short time, I managed to reach a partner relationship with the school director and a few teachers in Barra, as well as to establish a good collaborative environment with children inside the classroom and with a group of Roma adolescents (girls) outside the school, thanks to the extreme openness and support of the director herself. The situation was similar in the selected schools of Pécs, though there was less time engagement. Research results from the school context in Scampia came from activities (observation, collaborative research activities with students) that were included in my work in the classrooms within an educational project implemented by an association. Even 
though anthropologists often use similar techniques to approach difficult contexts, this is a very questionable position and as such it must be critically analysed.

\section{III.3 The researcher's position}

"A strict cultural approach is necessarily reflexive. We have no choice but to study that which we also make. There is no privileged position from which to escape culture. [..] all we claim we know proceeds from particular positions or instruments."(McDermottVarenne, 2006: 23) In this research, while I am looking for the traces of policies, my main interest revolves around the way in which local actors cope with top-down pressures and the local context and how can research itself lead to a process of reflection and transformation. As the main focus of the research is the deconstruction of terms used to approach the "question of Roma students", the terms and categories used by the research itself (e.g. Roma, periphery) and the researcher's position must be continuously (self) assessed. Throughout my work I focus on subjectivities and I reflect on multiple positionalities and the politics involved in the construction of my field. Thapar-Björkert and Henry, being non-white, 'Western' women, provide examples of their fieldwork during their investigation with the aim of rethinking the polarization that exists between the researcher and researched, a relation that is often labelled with categories such as powerful/powerless or oppressor/victim. This simplification can even be found in feminist research. These two researchers found themselves in much more complex and changing positionality as they developed their project (Thapar-Björkert and Henry, 2004). Cairns, based on an educational ethnography in rural settings, proposes to put the research at the intersection of feminist post-structuralism and cultural geography: "As a generative practice, ethnography does not simply 'take place', but participates in the active making of place a relational process that is on-going, contested, and enmeshed in networks of power. Feminist post structural scholars have forged important interventions into ethnographic debates by questioning ideals of authentic representation and challenging researchers to confront for their own implication within the politics of knowledge production.” (Cairns, 2013: 335.) This is not a simple attempt to balance power relations, but rather an approach that transforms the way we think and the language we use.

The researcher's (changing) performance often challenges precisely the same questions that are analysed in this research: an Eastern-European migrant woman in Southern-Italy, a gazhi in a Roma camp, a girl/woman alone in the periphery or camp, a mother of a Roma child that inspires different reactions. Something similar happens in Hungary: a researcher that goes to the periphery or lives abroad and returns to her hometown for research purposes, someone that is somewhere in-between being a native and a stranger, or who's too involved or too distant. The list goes on and the North-South, WestEast relations, ethnicity, gender or age aspects can be included. In this regard, achievements and limits of collaboration, my perceived and real position in the power relations of the local context, the results of the research seen as 'products' of an interaction and my shifting 
positionality when working locally and talking in international scenes are all important aspects of a critical engagement with the process and its results (Baracsi, 2016).

\section{CRItical AND Engaged at THE SAME Time?}

\section{IV.1 Challenges and limits of attempting to have an engaged position}

The field of educational ethnography has made precious contributions to educational policy research. It looks at policy research as cyclical process and "it offers too, a means of bridging the macro-micro gap since a study focused on the impact of a range of policies in the 'zone of implementation' will tend to expose constraints and influences of wider societal factors on what teachers do. [...] there has been a neglect of the experiences, perspectives and emotions of actors who are charged with the implementation of policy and the social, cultural, political, economic and emotional contexts in which it takes place." (Troman et al., 2006: vii-viii.) When I started my research in 2011, my original idea was to develop an action-based research in educational settings. Later on, I changed the 'label' of my research to collaborative ethnography, sometimes referring to it as collaborative action ethnography, as it is used, for instance, by Erickson in his study 'Studying Side by Side: Collaborative Action Ethnography in Educational Research’ (Erickson, 2006). I soon left the word 'action' behind, though, when I realized the amount of resources, teamwork and institutional commitment that the implementation of a community-based action research implies (Schensul et al., 1985), in line with the complexity of the issue. Nevertheless, collaborative research implies action and it may be different from participatory action research: the former involves participation in research activities and action is an outcome of the local 'politicisation' of questions addressed by the research.

Tension comes to the surface when trying to be both critical and engaged, i.e. when attempting to collaborate with many different actors in order to produce research knowledge that can be applied in the local context in some forms, while being committed to the criticism of categories widely used by the different actors with the purpose of revealing discriminative practices. On the other hand, this is exactly what made the research experience complex. First of all, when it is positioned according to its local 'utility', it has the potential to enable dialogue and the emergence of certain issues, and it implies very different ethical and epistemological standpoints that must always be analysed according to the existing power relations. It is difficult not to take a clear stand in reference to a certain group, but trying to understand several levels and sides in the same context necessarily entails a strong tension. An ethnographer - whether having an explicitly engaged approach or not - easily finds him/herself in a situation in which different actors challenge his/her responsibility, role, utility and capacity to intervene. Though on one hand, the need to intervene could be discussed along different ethical, methodological and epistemological standpoints, in practice, demand is usually very concrete and pressing. Moreover, it often leads to crossing the pre-imagined boundaries of a researcher's position, as well as 
changing roles. A position of engagement can be interpreted as a way of politicizing certain issues on the local level by highlighting them, thus giving place to a critical reflection on them.

As Kovai writes in her report of two schools based on a research carried out within the EDUMIGROM research project ${ }^{20}$ : "It is obvious that "Gypsyness", as the experience of the otherness, is not the difference itself. [...] Most likely, Gypsy problematics incorporate in pre-existing dynamics that we can approach more easily through the Gypsy question. In this case, this school finds it difficult to deal with - any kind of - experience of difference. [...] The Gypsy or Roma in both cases are interpreted in their relation to the so-called "norm" or "normal", as they question, challenge or cannot confirm the norms." (Kovai, 2011) The labels and categories (that derive from the relevant legislation) represent efforts made to describe, define and divide diverse from the "normal" students. I was looking at these taken-for-granted categories and tried to understand what is "cultural" in them: what is success, good behaviour and the meaning of being a good citizen in a certain context. The image of Roma students is not just the result of this differentiation, but is also found at the heart of its production. This led me to analyse how certain 'cultural elements' are put together in the imagined 'Roma students' and what are its local specificities. ${ }^{21}$ In my understanding, when the research finds or even creates challenging or conflicting situations around the actors and their role in the preservation of such categories and transgresses everyday practices (regarding communication and space, for example), it helps to gain a deeper insight of the researched questions. In the next section, using a series of relevant examples taken from the field, I attempt to interpret these situations.

\section{V.2. Transgression at the service of critical ethnography?}

a) "Maestra Kitti": moving in a crowded space.

When I started my fieldwork in the schools, the ambiguous situation of external figures and their role in the implementation of educational projects for Roma soon became the key points of my analysis. My own presence in the school actually helped me understand the unique characteristics of each context better. I suddenly found myself involved in the dynamics of each school, negotiating not only which where my activities but also the very grounds of my role as a researcher. I was compared to other figures like educators from NGOs by teachers, students and sometimes even by families. Some of them considered me to be trustworthy, while others didn't, and a series of different expectations were put on me. Of course, this happens in the case of 'traditional' ethnographies as well, but the simple fact that the teachers and students carried out a concrete activity with me

\footnotetext{
20 Ethnic differences in education and diverging prospects for urban youth in an enlarged Europe: A comparative investigation in ethnically diverse communities with second-generation migrants and Roma. www.edumigrom.eu

${ }^{21}$ About the implications of naming as Roma in a case of Sinti, see Setti, 2015
} 
allowed me become acquainted with the crowded space of institutional roles and projects, in which I had to renegotiate the limits of "my project" on a constant basis.

One day, when talking to a school deputy-director, I was explaining my research, emphasising that I was interested in seeing classes where there were Roma students, though I preferred to work together with the entire class. They showed their willingness to help me and I felt satisfied about the meeting. However, when we were specifying the details of my next visit, in which these activities would be implemented, they said: the next time you come that project for Roma students will have already started, so we could combine your activities with that. That was not the only time I was mistaken for an NGO worker. On the other hand, my research clearly benefited from these blurred lines: in one of the schools, a significant part of my empirical data came from activities carried out as part of an educational project implemented by an NGO. On another occasion, after having worked for long months on collaborative research with a group of children, I was talking to one of them when I realized that, to her, our research was just an activity among the wide range of project activities offered by NGOs.

After my initial concern of having failed in my research, I finally understood that it was not "my fault" and in spite of all my efforts for transparency and comprehensibility, I had to move according to the local concepts. It was then that they called me "teacher" given that the teachers often tried to emphasise the importance of my presence, referring to me as their colleague and also by stating that I was "Kitti, who came to make a project". In the meantime, I understood that getting into this labyrinth of roles is not something that hindered my research, but on the contrary, helped me to understand the tensions and negotiation processes between the different actors more thoroughly. In addition to this, it also portrayed the experience of local actors with researchers or educators in training. In the Neapolitan context the general approach to solve the Roma students' presence in class by having an additional person who works exclusively with them. This - at least partially - is the result of public projects that counted with the presence of cultural mediators (employed by NGOs), who in the former projects (and still in some cases) entered the classrooms, not knowing the Romani language and ended up providing activities only for Roma children (inside the classroom or in a separate room) and helping them to catch up with the activities. The whole design of these projects, and mainly the mediator role, created and preserved a special balance in which the mediators took on certain roles of teachers and social workers, which is quite similar to the support that children with special educational needs could receive. The only difference in this last case would be the educators' professional background. Reassigning the responsibility of Roma minors to associations based on the assumption that they know them better (i.e. their culture, the way in which they communicate) has been an obstacle for years that has opened a debate about inclusion in education. As I mentioned earlier, this situation is slowly, though not entirely, transforming. But even in situations where professional roles are more clearly defined, the presence of figures like a mediator, social worker, etc. always entail the risk of replacing the duties of some teachers or the social services as the actors try to reduce the problems 
and their own responsibilities. There are, of course, very good examples of collaboration and the role of a social worker highly depends on the profession's prestige in the given context, the professional background, official position (employed by the school or not) and the relevant regulation. In one of the elementary schools included in my research I was supposed to go to a young teacher's class, who - as other teachers said - had problems keeping children calm. This teacher was worried about how students would react to the presence of two young "teachers" (one being me) at the same time, so she invited the social worker to come in order to help keep the pupils quiet. From what I observed, this simple case unveiled a series of tensions that existed among teachers and in the teacher-student relation in the formers' (understandable) effort to keep a good image of the class.

\section{b) Challenging the rules of interaction}

Doing collaborative research with students destabilizes the previously established forms of everyday life in the school (both on behalf of teachers and students), and therefore often brings to the surface visible tensions. Usually, if the formal behaviour was too strong, there was more tension and violence would come up during the activities. One of the main concerns surrounding my presence was whether I could handle the students or not and draw limits. Teachers, in fact, often intervened during the research activities in those classes where balance was kept by strongly repressing conflicts. During an activity in the $8^{\text {th }}$ grade in Pécs when I asked something to a girl and did not understand her answer, she got angry and yelled at me. I reacted in a peaceful way and tried to explain the situation. Seeing this, one student said to another "look, she is cool, that girl yelled at her and she did not even shout back". At the same time, teachers considered that everything that happened could hinder the research activity and my main difficulty was to explain that this, in fact, was something relevant for the research. When I brought collaborative research activities to the students of that same class and asked them to conduct interviews with an imaginary student and then with one other, tensions related to their ethnic identity came to the surface. That is how from one single lesson I gained insight of the deepest conflicts between Roma and non-Roma students and the way in which Roma students refer to their "Gypsyness".

From what I noticed, there is a strong tension in some classrooms that is, at least partially, the result of a colour-blind, conflict-avoiding strategy. In Pécs, according to the interviews, regarding the Roma and non-Roma relation, there might be less open conflicts than between the different ethnic groups, namely the Boyash and Kolompár. Also, some of the interviewed Roma mothers stated that 'Hungarians' tend to act as 'Gypsies'. These are the same trends of the neighbourhoods: assimilation processes within the community are reinforced by the external ethnicisation of poverty. Those living in areas with a high presence of 'Gypsies' are seen and treated as 'Gypsies'. According to the parents' opinion, racism in classrooms comes mainly from the teachers and occasionally from the students.

The relation with space, the created spaces and the accepted or favoured ways of interaction, i.e. the exact meaning of collaboration and competition, strongly influence the 
situation of Roma students in the classroom. As a very basic and obvious point of comparison, the performative forms of resistance (and the noise level) in the classrooms are completely different in the two localities as well as in the two peripheries of Naples. The idea that one has to take his/her own space is much stronger in the Neapolitan schools, an attitude that is also encouraged by the teachers. The local (often neighbourhood-specific) interpretation of success and the accepted strategies strongly influence the classroom environment and the communication, including the locally accepted ways of expressing hostility. It is worth looking at the underlying processes that create or deny certain spaces from the different actors based on gender and race. The comparison between the two contexts allowed me to obtain a very interesting insight on this matter. While in the schools of Pécs some teachers seem to be dedicated to protecting the non-Roma children from the Roma children's "violent ways of communicating", as it is seen in that context,, the very same type of communication in a Neapolitan periphery does not appear to be as violent and is much more the common way that Neapolitan children use to communicate. The differing forms of communication create different non-inclusive spaces.

Doing collaborative research challenges space and interaction in a very simple way: it facilitates the communication of persons who do not normally communicate. One day, as some fifth graders were talking about their cognitive maps of the city in couples, I saw two children - a Roma boy and Neapolitan girl - laughing and not doing anything else. When I asked them what was going on, it turned out that they had never talked before between them, and laughter was their way of showing embarrassment. This case followed a long discussion with the teacher and an observation phase in the classroom. The teacher was convinced that Roma students were well integrated in the classroom, which is something that my first observations also confirmed. However, seeing that there were two students who had never talked to each other in years helped me understand better what was the integration concept that the teacher had, as well as the idea of what they considered to be a well-functioning class group, i.e. whether the students of a relatively small class should interact or not on a daily basis.

In one of the schools I found a very positive environment with a 'Roma supportive' director, and racism seemed to be "suspended" there. This was only partially true, though, as it greatly depends on the teachers themselves - if they have a different approach or try to hide their true opinions. In any case, although this school seemed to be a safe environment for the Roma children, a series of examples led me to think that it did not have a clear result beyond the school boundaries: there was an epidemic among the pupils and it stirred up a strong reaction among the parents, reinforcing racist narratives. Motivated by this health issue, they began to complain about the fact that Roma parents were collecting metal from the waste together with their children after school, implying that this had caused the epidemic. This meant that these Roma children, who were considered to be classmates within the school boundaries, as soon as they left the building and met their parents to go home, once again became 'those Roma from the camp'. I understood the significance of the 
episode of the epidemic while working on the interviews with students, as it came up among the questions.

Hence, collaborative research activities carried out with the students and supported by the teachers helped reveal racist issues, which became evident while drawing and explaining the mental maps of the city and even and, furthermore, when we were elaborating the interview questions. Also, the space created by these activities allowed the students to arrive to this issue, which is mostly avoided in normal school activities.

\section{c) The questions of an outsider: revisiting normality}

In the schools included in my research, the production of normality - given that they are located on the periphery - takes places based on the very few examples of the imagined 'normal students'. The latter, according to this imagery, are the ideal students. Pupils that represent this imagined and desired level are not many and the rest - and majority - of students are labelled as 'problematic'. One of the school directors told me: "the teachers do not want to accept that these are the students, they are attached to an imagined child that only a few students per class can confirm and they continue to teach only these students".

Teachers, educators and social workers often talk about Roma students as a "separate problem", though if we ask them about the other children they come up with similar remarks. The peripheries of Naples, which are considered as problematic and the children that grow up in these places are strongly stigmatised, are places that exemplify quite well how this reality reproduces 'the even more problematic other', namely the Roma students, i.e. the way the stigmas are passed on from Neapolitans to Roma. ${ }^{22}$ A critical and engaged research position and a transnational comparison can question what appears to be obvious to the local actors. My dialogues with teachers were usually based on the presumption - on their behalf - that we share the same concepts, therefore the simple questions I posed to them or my incomprehension helped them rethink ideas and practices that they had never questioned before.

On one occasion I had an interesting dialogue with a teacher who was very active and supportive throughout the research process. I asked her about the status of the Neapolitan language in the class. I had repeatedly heard other teachers blaming Neapolitan students for not speaking Italian - "they don't even speak their mother tongue” - because according to their point of view Italian should be the mother tongue of children who actually speak Neapolitan at home. The stigmatisation of the Neapolitan language has its

\footnotetext{
${ }^{22}$ It was interesting to conduct an interview with an NGO that works in the "Vele", the famous buildings of Scampia, which are inhabited by squatters. They problems regarding education that they mentioned were the same ones listed by those working with Roma children.
} 
roots in historical and social dynamics of the Italian context and the special situation of Naples.

\section{ConClusion}

Carrying out an engaged ethnography and studying side by side with the different interlocutors, means creating spaces of collaboration to collect research data and analyse it. These mechanism help gather information, perspectives, and interpretations that usually remain hidden. In order to do so, they often break the routine and introduce new channels and instruments of interaction that reveal the underlying processes that either allow or block the efforts of collaborating with the different actors. Nevertheless, these interventions are often very small and rather invisible. In spite of this, by putting in motion certain questions, they have the potential to reveal power relations based on age, gender, race, class, or different professional roles within the field and how these change within the same context according to the situation, place and institutional framework. During my fieldwork, several times I found myself having discussions with teachers, in which we questioned something that seemed very evident in that context. In other cases, the collaborative methods in the classroom created out-of-order moments or provided immediate information about the underlying conflicts. The collaborative approach can bridge the gaps that appear through the identification processes of different actors, including the differences in the languages they use. On the other hand, the limits and risks of these deconstruction attempts and the difficulties of reshaping power dynamics must be taken into account. However, an engaged ethnography can help reshape the interpretation and utilization of terms related to culture and integration at a local level.

From my understanding, the reflection process that took place together with the different actors contributed to the actors' politicization of certain issues in a very simple way: they put them on the explicit agenda. In this regard, observations on the relation of ethnography and transnational activism seem to be quite relevant: "the role of ethnography should be understood not in terms of explanation or representation, but as translation and weaving, processes in which the ethnographer is one voice or participant in a crowded field of knowledge producers. Ethnographic translation enables the ethnographer's participation in the creation of new and different worlds and is a vital form of political intervention." (Casas-Cortés et al., 2013: 199) In ideal situations, this approach also replaces the need to communicate directly with policy-makers, as it is something that is carried out by local actors. ${ }^{23}$ At the same time, the research should understand the multiple positionality of the researcher and the subject that is being researched, and should avoid becoming an attempt of giving voice to the 'marginalized ones' as in that way it does nothing more than reproduce the same powerful-powerless distinction. Roma education cannot be seen as the

\footnotetext{
${ }^{23}$ Of course, there are many examples of collaborative research with local policy-makers and there is even a recent example on one of my field sites. (see Zoppoli \& Saudino, 2012)
} 
issue of Roma students and families: it is an issue of teachers, non-Roma students, families, NGOs, social services, etc. Moreover, in a collaborative process, power structures and discrimination should be understood thoroughly, which means that the researcher is under the constant pressure of having to reconsider his/her choices.

\section{REFERENCES}

AGAMBEN, G. (1996/2008). “Che cos`è un campo?”, In AGAMBEN, G.: Mezzi senza fine. Note sulla politica. pp. 35-41, Bollati Borenghieri, Torino.

AGIER,M. (2002). "Between War and City: Towards an Urban Anthropology of Refugee Camps” Ethnography 3 (3), pp. 317-341. https://doi.org/10.1177/146613802401092779

BAKÓ B. (2009). “Mentális határok. A csobánkai romungro gyerekek iskolai kudarcai.”, in BESZÉLŐ 14. (11), pp. 14-26.

BARACSI, K. (2016). "Engaged and collaborative research on urban margins: reflections on research positions, relations and categories", Conference paper, presented on June 10, 2016 in Bergamo at the Ethnography and Qualitative Research Conference (in file with the author).

BELMONTE, T. (1974/1983). "La fontana rotta”. Vite napoletane,

CAIRNS, K. (2013). "Ethnographic locations: The geographies of feminist post-structural ethnography". Ethnography and Education 8(3), pp. 323-337. https://doi.org/10.1080/17457823.2013.792675

CASAS-CORTES, M., OSTERWEIL, M. \& POWELL, D. (2013). "Transformations in Engaged Ethnography: Knowledge, Networks and Social Movements," in JURIS, J. and KHASNABISH, A., eds., Insurgent Encounters, pp. 199-228. Duke University Press: Durham https://doi.org/10.1215/9780822395867-009

DINES, N. (2012a). "Beyond the aberrant city. Towards a critical ethnography of Naples", Lo Squaderno 24.

DINES, N. (2012b). Tuff City. Urban Change and Contested Space in Central Naples. Berghan Books.

ERICKSON, F. (2006). "Studying side by side: 'Collaborative action ethnography in educational research."”, in G. SPINDLER \& L. HAMMOND, eds., Innovations in educational ethnography: Theory, methods and results, pp. 235-257. Mahwah, NJ: Lawrence Erlbaum Associates 
FEISCHMIDT, M., V. MESSING, \& M. NEMÉNYI. (2010). "Ethnic Differences in Education in Hungary: Community Study.” EDUMIGROM Community Studies. Budapest: Central European University, Center for Policy Studies.

GOBBO, F. (2009). “The INSETRom project in Turin (Italy): outcomes and reflections”. Intercultural Education, 20 (6), pp. 523-535. https://doi.org/10.1080/14675980903448569

HOHTI, R. (2016). “Children writing ethnography: children's perspectives and nomadic thinking in researching school classrooms”. Ethnography and Education. 11(1), pp. 74-90. https://doi.org/10.1080/17457823.2015.1040428

CECÍLIA, K. (2011). “A “cigány osztály” és az egyenlőség uralma”. Beszélő, 16(7).

LAINO, G. (2005). "Italy: the Scampia discrict in Naples”, in CIAFFI, D. (ed.) Neighbourhood housing debate. F. Angeli, Milano, pp. 180-200.

MILSTEIN, D. (2010). "Children as co-researchers in anthropological narratives in education”, Ethnography and Education, 5(1), pp. 1-15. https://doi.org/10.1080/17457821003768406

MCDERMOTT, R. \& VARENNE, H. (2006). "Reconstructing Culture in Educational Research”, in G. SPINDLER \& L. HAMMOND (Ed.) Innovations in educational ethnography. Mahwah, NJ: Lawrence Erlbaum Associates, pp. 3-31.

PARDO, I. (1996). Managing Existence in Naples: Morality, action and structure. Cambridge University Press. https://doi.org/10.1017/cbo9780511621802

PICKER, G. (2012). “Territori postcoloniali ai limiti. I campi per rom in Italia e Francia tra doxa e storia”, in GALEOTTI, M.E. \& CEVA, E. (Eds.) Lo spazio del rispetto. Milan: Bruno Mondadori. pp. 96 -121.

PICKER, G. \& PASQUETTI, S. (2015) "Durable camps: the state, the urban, the everyday”. City, 19(5), pp. 681-688. https://doi.org/10.1080/13604813.2015.1071122

PIERRO, B., FERULANO, E. \& BARACSI, K. (2014). “Residence: Nowhere”, Going Nowhere? Western Balkan Roma and EU Visa Liberalisation. Roma Rights Journal, January 2014.

PLESNER, U. (2013) "Building Networks with Vague Intentions: A Vocabulary of Enrolment and Negotiations in Collaborative Research Practice”, in PHILLIPS, L. KRISTIANSEN, M. VEHVILÄINEN, M. \& GUNNARSSON, E. (Eds), Knowledge and Power in Collaborative Research: A Reflexive Approach. Routledge, New York, pp. 236-254.

SALETTI SALZA, C. (2003). “Bambini del "campo nomadi". Romá bosniaci a Torino”. CISU.

SAVIANO, R. (2006). Gomorrah, Mondadori, Milano. 
SETTI, F. (2015). "The implications of 'naming' on Roma and Sinti right to education and social inclusion: an ethnography of education among a Sinti family network”. Intercultural Education Journal, 26(2), pp. 114-130. https://doi.org/10.1080/14675986.2015.1023011

SIGONA, N. \& MONASTA, L. (eds.) (2006). Cittadinanze Imperfette. Rapporto sulla discriminazione razziale di rom e sinti in Italia. Edizioni Spartaco.

SIGONA, N. (2011). "The governance of Romani people in Italy: discourse, policy and practice”. Journal of Modern Italian Studies, 16 (5), pp. 590-606. https://doi.org/10.1080/1354571X.2011.622468

SIGONA, N. (2015). “Campzenship: reimagining the camp as a social and political space”. Citizenship Studies, 19(1), pp. 1-15. https://doi.org/10.1080/13621025.2014.937643

THAPAR-BJORKERT, S. \& HENRY, M. (2004). "Reassessing the research relationship: location, position and power in fieldwork accounts”. International Journal of Social Research Methodology, 7 (5), pp. 363 -381. https://doi.org/10.1080/1364557092000045294

TROMAN, G. JEFFREY, B. \& BEACH, D. (2006). "Researching Education Policy: Ethnographic Experiences”. The Tufnell Press.

VARENNE, H. \& MCDERMOTT, R. (1998) Successful failure: The school America builds. Boulder, CO: Westview.

WALFORD, G. (2008). How to do Educational Ethnogprahy. Ethnography and Education. Tufnell Press, London.

ZOLNAY J. (2008) “Pécsi stratégiák”, in Neumann Eszter - Zolnay János (ed.) Esélyegyenlöség, szegregáció és oktatáspolitikai stratégiák Kaposváron, Pécsen és Mohácson. EÖKIK, Bp pp. 49-101.

ZOPPOLI, G. \& SAUDINO, F. (2012) “I rom in commune”. I Quaderni del Barrito. http://www.comune.napoli.it/flex/cm/pages/ServeAttachment.php/L/IT/D/e\%252F0 \%252F2\%252FD.1bf651902bd496f47151/P/BLOB\%3AID\%3D17305 